\title{
Pediatric Sapovirus Gastroenteritis in Ireland-Disease Virulence, Viral Dual-Infection, and Regional Seasonal Trends
}

\author{
Zakaria Barsoum ${ }^{1}$
}

Received: 4 January 2021 / Accepted: 19 February 2021 /Published online: 8 March 2021

(C) Crown 2021

To the Editor: Sapovirus (SaV) gastroenteritis (GE) occurs year-round, with the highest proportion from March through July predominantly affecting infants and toddlers $[1,2]$.

During 2016/2017, 150 children $\leq 3$ y, presenting with vomiting and diarrhea were recruited in our region, and had their stool tested for adenovirus (AdV) DNA genome by polymerase chain reaction (PCR) testing and by reverse transcription real-time PCR of RNA genome for rotavirus (RV), norovirus (NoV), astrovirus (AsV) and $\mathrm{SaV}$, using the Roche MagNA Pure 96 as per manufacturer's protocol [3]. Consent and ethical approval were obtained.

Vesikari scoring system assessed disease severity or virulence (Supplementary Table 1).

$\mathrm{SaV}$ was confirmed in $9(6 \%)$ stool samples following RV, AdVF, and NoV. Six were male; 5 were $\leq 1$ y of age; 6 severe, 2 moderate and 1 mild, with a peak of $\mathrm{SaV}$ infections noted during the first week of May (2 cases of the total 3 samples tested for viral pathogens).

Viral dual-infection was noted in two male infants, both severe. Triple infection with NoV GII and AdVF was confirmed in 1 case, and the second case was due to dualinfection with RVG1P[8] (Rotarix TM) which was detected about $16 \mathrm{~d}$ following the second dose of RV vaccine.

A small sample size from one region along with strict adherence to hygienic measures may have contributed to the absence of nosocomial $\mathrm{SaV}$ infections in our study.

Two short episodes of $\mathrm{SaV}$ infection, each lasting $2 \mathrm{wk}$ in May and August were noted during 2016/2017, with one short $\mathrm{SaV}$ season, that started in November/December, peaked in
December (12.5\%), and lasted $5 \mathrm{wk}$. This may reflect an overestimation of the analysis due to the limitation of a small sample size of one geographical location.

For proper determination of $\mathrm{SaV}$ seasonal trends in our country, we would recommend further research covering larger sites with greater sample size.

Supplementary Information The online version contains supplementary material available at https://doi.org/10.1007/s12098-021-03711-x.

\section{Declarations}

Ethical Approval Obtained from the Clinical Research Ethical Committee before study commencement.

Conflict of Interest None.

\section{References}

1. Dennehy PH. Viral gastroenteritis in children. Pediatr Infect Dis J. 2011;30:63-4.

2. Chhabra P, Payne DC, Szilagyi PG, et al. Etiology of viral gastroenteritis in children $<5$ years of age in the United States, 2008-2009. J Infect Dis. 2013;208:790-800.

3. Tiemessen CT, Nel MJ. Detection and typing of subgroup F adenoviruses using the polymerase chain reaction. J Virol Methods. 1996;59(1-2):73-82.

Publisher's Note Springer Nature remains neutral with regard to jurisdictional claims in published maps and institutional affiliations.

Zakaria Barsoum

doctorzakaria@yahoo.com

1 Department of Pediatrics, South West Acute Hospital, 124 Irvinestown Rd, Enniskillen, Northern Ireland BT 74 6DN, UK 